\section{Expansion and Development of Private Higher Education in East Central Europe}

\section{Hans C. Giesecke}

Hans C. Giesecke is president of the Tennessee Independent Colleges and Universities Association, 611 Commerce St., Nashville, TN 37203, USA. Fax: (615) 242-8033; e-mail: <gieseckeH@ticua.org>.

$\mathrm{P}$ rivate higher education has expanded dramatically in a number of East Central European countries since the dissolution of the East Bloc. Between 1990 and 1997, the Czech Republic, Hungary, Poland, and Romania, for example, have seen average annual growth rates of nearly 60 percent each year. In these countries, total private-sector enrollments have expanded from less than 12,000 students in 1990 to more than 320,000 students in fall 1997.

The steep growth curve of private higher education in East Central Europe is a clear signal of the public's frustration over the availability of higher education offerings in the state-operated sector. It reflects the extent of pent-up demand for academic programs in fields that were not available to students until communism's demise. Moreover, the substantial enrollment increases posted by private-sector institutions are indicative of the former East Bloc countries' relatively low "college-going" rates and the increasing public recognition that market-oriented education and training are necessary for individual competitiveness in the new economic environments now coming into play.

It is not surprising, therefore, that most of the degrees offered through the burgeoning private sector are in high-demand fields such as business and management, computer science (informatics), and pedagogy (the teaching of foreign languages). The clear emphasis is on practical education of immediate use in the workforce. Many institutional leaders of the emerging private sector report that these subject areas are still largely ignored by the faculties of state-operated universities.

While still considered the primary academic degree of higher education in East Central European countries, the "magister" is now losing some of its preeminence to two lower-status degrees that are relatively new to the region. The first of these is termed the licentiate, a three-year professional degree with a practical focus. It is offered primarily in business and management and in a number of technologically oriented fields. The second new degree in the region is the baccalaureate. This is a four-year degree that is frequently offered in economics, the humanities, pedagogy, and in several sci- ence and engineering fields. While it is a mainstay of higher education offerings in North America, the baccalaureate degree is a near revolutionary concept to many European academics. To a certain extent, the growth of these new degree types is related to difficulties many new private institutions encounter in obtaining government approval to offer the magister degree. Accordingly, many start-up institutions begin operations by offering the licentiate and/or the baccalaureate degrees.

On the matter of quality control, it is evident that true voluntary accreditation by autonomous peer accrediting bodies has not yet taken hold in these countries. With the possible exception of Romania, the accreditation process has yet to become an integral part of the higher education culture in this region. One important factor is that the leaders of the accrediting bodies in these countries often are political appointees of the ruling political parties, whose educational agendas they carry out through the accreditation precess. In the near term, the private sector will be preoccupied largely with meeting standards and guidelines for operation imposed by the national ministries of education, and, therefore, may not be too concerned with the accreditation process.

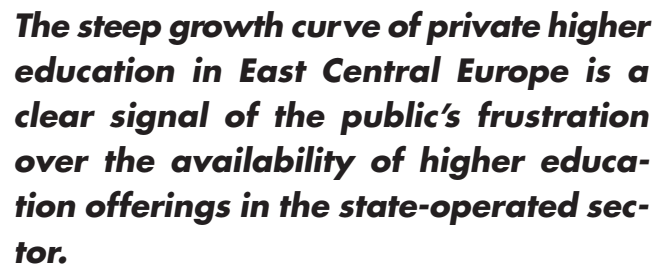
education in East Central Europe is a clear signal of the public's frustration over the availability of higher education offerings in the state-operated sector.

With respect to budgets, it is quite clear that institutional operating revenues are derived heavily from tuition and fees. This fact makes the operational future of many new private institutions largely dependent on demographic and market forces, which could easily swing against them in the next several years. If the current fad of management education suddenly loses favor with the public, for example, as much as 50 percent of the total enrollment in the private sector could dissipate quickly.

By American standards, tuition and fee charges are very low among the private institutions in these countries. ${ }^{1}$ Yet, even the average per semester charge in each country represents a substantial portion of the average personal income. The key question concerns where students are obtaining the resources to pay for tuition and 
East Central European Higher Education Enrollment Figures, 1996-97

\begin{tabular}{|c|c|c|c|c|c|c|c|}
\hline & $\begin{array}{c}\text { Total } \\
\text { P opulation }\end{array}$ & $\begin{array}{l}\text { P opulation } \\
\text { Growth Rate } \\
\text { (A nnual \%) }\end{array}$ & $\begin{array}{r}\mathrm{P} \text { er } \\
\mathrm{P} \text { opul } \\
\text { some } \mathrm{Po} \\
\mathrm{E} \mathrm{d} \\
\text { Males }\end{array}$ & $\begin{array}{l}\text { tof } \\
n \text { with } \\
\text { con dary } \\
\text { ion } \\
\text { Females }\end{array}$ & $\begin{array}{l}\text { Total En rollmen } t \\
\text { S tate-Op erated } \\
\text { Higher Education }\end{array}$ & $\begin{array}{l}\text { Tot al En rollmen } t \\
\text { P rivat e, A pp roved } \\
\text { Higher E ducation }\end{array}$ & $\begin{array}{c}\text { P ercen tof } \\
M \text { arket S hare } \\
\text { in Private } \\
\text { S ector }\end{array}$ \\
\hline Czech Rep ublic & $10,321,000$ & 0.27 & 8.2 & 4.0 & 139,774 & 700 & 0.5 \\
\hline Hun gary & $10,480,000$ & -0.15 & 9.3 & 5.0 & 165,000 & 26,650 & 13.9 \\
\hline $\mathrm{P}$ dan d & $39,010,000$ & 0.29 & 7.2 & 4.4 & 645,000 & 209,000 & 24.5 \\
\hline Rom an ia & $23,690,000$ & 0.26 & 6.7 & 4.6 & 235,000 & 85,000 & 26.6 \\
\hline F ou r-Nation To tal & $83,501,000$ & & & & $1,184,774$ & 321,350 & 21.3 \\
\hline F ou r-Nation Means & $20,875,250$ & 0.17 & 7.85 & 4.5 & 296,194 & 80,338 & 21.3 \\
\hline U.S. Total & $268,200,000$ & 1.03 & 36.9 & 28.0 & $11,092,374$ & $3,169,407$ & 22.2 \\
\hline
\end{tabular}

Sources: See note 2.

fees absent national loan and grant systems. While a new student loan system has been inaugurated in Poland and one is under review for Hungary, their establishment does not explain the dramatic enrollment growth of the past seven years. To pay the costs of higher education in the private sector, students are somehow marshaling funds from a variety of sources and investing in their future.

According to data collected in the region through a survey in fall 1997, high growth rates are occurring among comprehensive universities, professional studies institutions offering three- or four-year degree programs, and general studies colleges focusing on teacher training. Some differences exist between countries in terms of the growth rates by institutional type.

Survey data reveal that many new private institutions now operating in these countries are operationally frail and would be rated as marginal operations by most Western higher education analysts. Of the 69 institutions for which data were obtained in Poland and Hungary, more than two-thirds were rated low in both viability and legitimacy. The findings suggest that the vast majority of private institutions in these countries remain highly vulnerable to a variety of market and policy forces and could crumble or wither if circumstances tilt against them.

Despite such operational weakness, one of the strongest attributes of the private sector in this region is the pioneering spirit that has enabled institutions to grow and develop in ways that could not have been imagined a decade ago. There is ample evidence of innovation in course design, programming, and scheduling. It is clear that the emerging private sector in these countries is committed to breaking the rigid higher education mold cast by the communist governments since World War II and to creating a more open approach with much wider options for students.

Several sources depict the private sector as striving to attain viability and legitimacy within a higher educa- tion context and overcome its image of inferior quality. The quality of instruction in the emerging private sector has become a sensitive topic. One key revelation is that the majority of faculty members teaching in the state-operated and private sectors are one and the same-working by day at state-operated institutions and by night at private ones.

Some analysts suggest that the chief difference between the sectors appears to lie in the level of student quality, as many students in private institutions were denied admission to state-operated universities. In the eyes of a highly status-conscious higher education establishment, the majority of private-sector students are not considered of sufficiently high academic caliber to be admitted to traditional state-operated universities.

Nevertheless, there is vastly insufficient capacity to meet the demand for higher education in these countries. Given the opportunity to step in and provide services, the private sector has come on so strong that the eventual impact may be a sea change in how higher education programs are structured and delivered in the region.

\section{It is evident that true voluntary accredi- tation by autonomous peer accrediting bodies has not yet taken hold in these countries.}

A key factor in the success of the private sector in these countries is the willingness of current and future students to invest in their future by paying higher tuition and fees. This trend indicates how determined students are to obtain market-based professional skills for long-term gain at the cost of significant short-term fi- 
nancial sacrifice. This development has pervaded North American higher education for much of the 20th century, but it is an idea that has taken hold in East Central Europe only in the last nine years. The extent to which the concept of short-term personal sacrifice for longterm benefit becomes part of the educational culture of these countries will impact how many of these private institutions flourish and how many die.

Another factor in the long-term viability of the private sector of higher education involves the extent to which the institutions are so closely tied to the character and personality of their founders. The majority of these institutions were the creations of one or two persons of vision and energy. However, there are major questions about what will happen to these institutions when the founders decide they want to pursue other interests or simply to retire from an institutional leadership role.

In summary, the issues and concerns of the new private institutions of higher education in East Central Europe are remarkably similar to those faced by many private-sector institutions in North America and elsewhere. The chief difference lies in the political, social, cultural, and economic circumstances. Indeed, the new private institutions of East Central Europe tend to be even more hierarchical than those in North America, with an established pecking order of institutions that is largely resistant to change. As they wage a daily battle for both viability and legitimacy, many of these fledgling institutions will remain highly vulnerable to market and policy forces. The extent to which these institutions are able to surmount the operational challenges of their infancy will determine whether the privatization movement will be one of growing importance for the region or one that is relegated to a footnote in the annals of European higher education.

\section{Notes}

1. Mean annual tuition and fee charges for the 1997-98 academic year for private institutions in the Czech Republic, Hungary, and Poland were U.S.\$1,406.

2. The main sources for this table are: Education Indicators: An International Perspective (Washington, D.C.: U.S. Department of Education, 1996); Mark Lazar, ed., $A$ guide to Higher Education in Eastern and Central Europe (New York: Institute of International Education-East Central Europe Regional Office, 1996); Hans C. Giesecke, Survey of Private Institutes and Universities in East Central Europe [a survey 101 private institutions in the Czech Republic, Hungary, and Poland] (Washington, D.C.: National Association of Independent Colleges and Universities, 1997); ASG: Database Europe <http://www.asg.physik.uni-erlangen.de/ europa/indexeng.html>.

\section{Ideas on Higher Education Funding: Internal Financing of Student Loans}

\section{Arthur M. Hauptman}

Arthur M. Hauptman is a consultant specializing in higher education finance. He has taught in the higher education program at Boston College. Address: 2701 N. Upshur Street, Arlington, VA 22207.

$M$ any countries are now either considering whether to impose tuition fees for the first time or substantially increasing what have been nominal fees in the past. How students and their families will pay for these fee increases is a critical issue. Financial aid, particularly loans, is being looked to as the primary means for helping students and their families meet some if not most of these additional expenses.

Officials in these countries may wish to consider an innovative source of loan capital in this regard-the tuition fees themselves. Internally financed loan arrangements of this nature can confer the important benefits of reducing the interest costs to borrowers and the amount of government subsidy required to make student loans financially feasible for potential borrowers.

A key component in any student loan program is the source of capital. At least 50 countries are reported to have student loan programs of one form or another-most use either government funds or private banks as their source of capital. Government and private financing have the obvious advantages of ensuring that sufficient loans are available and of involving entities experienced in the intricacies of raising and dispensing capital.

On the negative side, while most governments may be well versed in raising funds through debt financing, they are typically far less familiar with and efficient in the processing of loans. They are worse still in servicing and collecting student loans; indeed, most government-administered programs have notoriously high default rates. Also, in order to minimize subsidy levels, government-financed student loan programs typically charge interest sufficient to cover the government's cost of borrowing as well as administrative costs.

Private-sector lenders, on the other hand, require rates of return on student loans that are typically far higher than what most students can afford. To make loans politically acceptable, governments have to provide funds to buy down the interest rate, thereby substantially increasing the costs to taxpayers of sponsoring the loans. Governments also can keep the interest at below market rates by assuming most or all the risk of borrower default and other forms of nonpayment. However, this, of course, further increases the cost of student loans to the public purse and is frequently the largest subsidy cost in the entire program. 